\title{
LOS PRINCIPIOS DEL DERECHO EUROPEO DE CONTRATOS Y EL INCUMPLIMIENTO ESENCIAL. SÍNTESIS COMPARATIVA CON EL ORDENAMIENTO JURÍDICO CHILENO
}

\author{
EDUARDO JEQUIER LEHUEDÉ ${ }^{*}$
}

RESUMEN: Este trabajo trata del creciente fenómeno de armonización de las diversas regulaciones y normativas de Derecho privado en Europa, apuntando en particular a las iniciativas doctrinales que en concreto se han ocupado de la figura del incumplimiento esencial en el Derecho contractual y de su integración sistemática en base a los principios y fundamentos comunes que sobre tal materia se reconocen en el Derecho europeo comparado, dando forma y contenido a lo que actualmente se reconoce como un "Derecho Contractual Europeo". Se ocupa también de analizar comparativamente los principios y fundamentos apuntados en relación con las normas del Código Civil chileno sobre incumplimiento de las obligaciones, procurando definir las similitudes y diferencias entre ellos y las de ambos con regulaciones comparadas sobre la misma materia.

PALABRAS CLAVE: Derecho contractual europeo - principios de Derecho contractual - incumplimiento de obligaciones - incumplimiento esencial.

\section{The Principles of The Contractual European LaW AND THE ESSENTIAL NON-FULFILLMENT. COMPARISON WITH THE CHILEAN LEGAL SYSTEM}

ABSTRACT: This work deals with the growing phenomenon of balancing diverse regulations and rules of private rights in Europe. It aims at the doctrinal initiatives that state the figure of the essential non-fulfillment in

\footnotetext{
Abogado. Magíster en Derecho de la Empresa, Pontificia Universidad Católica de Chile; profesor de Derecho Comercial y Económico, Universidad Católica del Norte, sede Coquimbo; Diploma de Estudios Avanzados por la Universidad de Valencia (España). Actualmente trabaja su tesis doctoral bajo la dirección de la Profesora Dra. Silvia Barona Vilar. Becario del proyecto Mecesup UCN0301 de la Universidad Católica del Norte y de la Universidad de Valencia. Correo electrónico: ejequier@ucn.cl

Fecha de recepción: 5 de diciembre de 2008.

Fecha de aprobación: 1 de julio de 2009.
} 
Contractual Law and its systematic integration based on principles and common bases that are recognized over such matter in the comparative European law, thus giving shape and content to what is currently known as a "European Contractual Law". The article comparatively analyzes the principles and bases in relation with the rules of the Chilean Civil Code about non-fulfillment of the obligations, defining similarities and differences among them with compared regulations about the same matter.

KEY WORDS: Contractual European Law - Principle of Contractual Law - non-fulfillment of obligations - essential non-fulfillment.

\section{INTRODUCCIÓN}

La experiencia de otros, labrada a fuerza de tropiezos como suele ocurrir en los más variados ámbitos del entramado social, sirve en ocasiones como variable a considerar - a veces por vía ejemplar- en todo proceso de análisis y desarrollo jurídico-institucional de los pueblos en general, aun cuando aquella exhiba particularidades y matices que no puedan extrapolarse exacta y necesariamente a la realidad o tradición propia que se atiende.

La anterior observación -y no es más que eso- me ha motivado a realizar un breve trabajo de investigación y análisis de los diversos principios fundamentales que dan forma y contenido a lo que la doctrina europea reconoce hoy como un "Derecho Contractual Europeo", cuyos principios comunes y fundamentales, más que la simple manifestación de una inquietud aspiracional de juristas y estudiosos especializados (como lo fue efectivamente en sus orígenes, según veremos), constituyen actualmente una realidad concreta para algunos autores, aplicables por ende a todas aquellas relaciones contractuales en que las partes así lo quieran y estipulen.

Entre los pilares que estructuran este "Derecho Contractual Europeo", pues, se encuentran los denominados "Principios de derecho contractual europeo" -PECL ${ }^{1}-\mathrm{y}$, entre ellos a su vez, la figura del incumplimiento esencial del contrato por alguna de las partes.

Este último aspecto, que será en definitiva el objeto del presente trabajo, se inserta entonces en un marco dogmático y de desarrollo doctrinal del derecho europeo que resulta de interés abordar, pues ello nos permitirá comprender el origen de tal instituto y, desde allí, sus fundamentos y objetivos concretos. Del mismo modo, analizaré comparativamente la figura del incumplimiento esencial, en sus diversas manifestaciones y como principio de un Derecho europeo de los contratos, según se dijo, a la luz

Principles of European Contract Law. 
de la normativa chilena sobre Derecho de las obligaciones ${ }^{2}$, contenida en el Código Civil, para definir así semejanzas y diferencias.

\section{1) HACIA UN DERECHO PRIVAdo EUROPEO; BREVE SÍNTESIS DE UN EXTENSO RECORRIDO}

\section{(1.1) ORIGEN Y FUNDAMENTOS DEL DERECHO CONTRACTUAL EUROPEO}

Desde su creación hasta hoy, la Unión Europea ha debido enfrentar grandes desafíos a la hora de implementar orgánica y funcionalmente un sistema de efectiva convivencia y complementación entre sus diversos Estados miembros. Con el correr de los ańos, por lo demás, la incorporación de nuevos países a la Unión no solo ha multiplicado sus exigencias sino que las ha llevado también a niveles de creciente complejidad, haciendo cada vez más difícil encontrar mecanismos adecuados de solución que armonicen, al mismo tiempo, con los requerimientos del conjunto y de cada una de sus partes.

En su espectro económico, lo anterior presupone sin duda el diseńo de un amplio marco regulatorio supranacional y/o de transposición normativa que asegure el efectivo funcionamiento de un sistema que consulta, entre sus bases fundamentales, la unidad de mercado y la libre circulación de bienes, servicios, personas y capitales en todo el ámbito de la Unión. Pero al mismo tiempo -y con igual grado de importancia-, resulta indispensable estructurar además un sustrato jurídico-privado de común aplicación que permita y facilite ese libre flujo de bienes, servicios y capitales, lo que constituye por cierto una tarea nada fácil si consideramos que estos últimos están destinados a la circulación, comercialización, explotación y consumo en países de las más variadas costumbres y raigambres históricas, culturales, idiomáticas y, por cierto, jurídicas.

El fenómeno apuntado ha traído consigo entonces, amén de sus evidentes ventajas de crecimiento estructural, una serie de retos y exigencias económicas y jurídicas que, cada vez con más urgencia, reclaman del Derecho privado una base o núcleo común o transnacional, que dé solución al creciente tráfico jurídico-económico que este crecimiento requiere y que elimine o reduzca, consecuencialmente, los grandes obstáculos que surgen de las diferencias entre unos y otros ordenamientos (con los costes consiguientes). El derecho privado europeo, recordemos, se compone actualmente de los respectivos derechos nacionales de los países miembros (con tradiciones jurídicas muy distintas, como ocurre con el derecho civil

2 Para el Derecho de las obligaciones, que corresponde a una tradición de derecho continental europeo derivada del Derecho romano y plasmada, claramente, en ordenamientos como el francés y el alemán, el contrato no es más que una de las fuentes de las obligaciones. 
continental y el sistema del common law); de un importante número o cuerpo de normas de derecho comunitario, contenidas en igual cantidad de Directivas y Reglamentos que, por razones evidentes, no armonizan muchas veces con las legislaciones de cada Estado; y los Convenios Internacionales firmados por los distintos países miembros.

Sin embargo, y como seńala García ${ }^{3}$, las principales dificultades que enfrenta esta tarea de armonización normativa consisten en definir (a) cuáles son las materias que deben unificarse, (b) con qué fuerza vinculante debe hacerse esta unificación, y (c) cuál es la mejor forma de salvar las diferencias estructurales que existen entre los sistemas jurídicos del civil law y el common law.

En lo que sigue del presente trabajo nos dedicaremos a mencionar simplemente los hitos principales que se advierten en este largo recorrido de evolución doctrinal y normativa en el ámbito del derecho privado europeo, para detenernos finalmente en los PECL y, entre ellos, en el denominado incumplimiento esencial.

\section{(1.1.1) Los pilares del Derecho privado europeo}

Como señala Schulze ${ }^{4}$, tres son los pilares principales del Derecho privado Europeo, a los que denomina "textos básicos":

En primer lugar, la legislación de la Unión Europea -UE- sobre Derecho privado y, concretamente, el Tratado de la UE y la legislación comunitaria sobre aspectos medulares de Derecho civil y Derecho mercantil, como las Directivas que se han ocupado de la protección de los consumidores y trabajadores, la equiparación jurídica entre hombre y mujeres en la vida profesional, la protección de la privacidad de las personas y el cuidado y preservación de los bienes culturales de cada país miembro. Como apunta el autor, esta normativa ha afectado sustancialmente principios y aspectos jurídicos centrales en materia de Derecho privado en general, como ocurre con la libertad para contratar, la protección de la propiedad y el concepto mismo del contrato; y ha generado también cambios en materias relevantes como el tratamiento normativo de las cláusulas abusivas, el concepto de bienes inmuebles, las garantías en el contrato de compraventa, el incumplimiento moroso, la indemnización de perjuicios y otros tantos temas fundamentales.

García Garnica, María del Carmen (2002). "Consideraciones sobre la unificación del Derecho Privado Europeo", en Aranzadi Civil, No 7. Disponible en http://nuevo.westlaw.es/ wles/app/document?docguid=I285e17c0c73911 db8f5d010000000000\&srguid=ia744800e0 000011 ae5c6b41c571e71e2 [fecha de consulta: 02 de julio de 2008].

Schulze, Reiner (2003). "El Derecho Contractual Europeo y sus textos básicos", en AA.VV. Bases de un Derecho contractual europeo, Valencia: Tirant lo Blanch, p. 629. 
Más concretamente aun, en este nivel institucional destaca la preocupación del Parlamento Europeo -PE- en sus Resoluciones de 26 de mayo de $1989^{5}$ y 6 de mayo de $1994^{6}$, respectivamente, en las que manifestó su interés en buscar un núcleo común de Derecho contractual europeo. Con ese propósito, las Resoluciones mencionadas encargaron en ese momento, aunque tímidamente y de manera aparentemente ambigua, la realización de los estudios preliminares tendientes a la creación de un Código Civil Europeo o, en último término al menos de un Código Europeo de Contratos. Sin embargo, y como apunta García ${ }^{7}$, la timidez que mencionamos no fue sino una muestra de prudencia del PE, en un momento en que la tarea de armonización que comentamos era apenas una idea incipiente -al menos en este ámbito institucional- que traía como consecuencia, sin embargo, cambios fundamentales en el proceso de unificación jurídica de la UE.

Años después, la Comisión de la CE tomó la decisión de dar un impulso decisivo al proceso de estudio para la codificación de un Derecho general de contratos europeos, constatando por una parte las dificultades que ha presentado el sistema de Directivas ${ }^{8}$ en su incardinación con los Códigos de cada país y, por otro lado, la insuficiencia de los instrumentos de Derecho internacional -como la "Convención de las Naciones Unidas sobre compraventa internacional de mercaderías" y el "Convenio de Roma sobre el Derecho aplicable en las obligaciones contractuales"- para dar respuesta a los diversos problemas de relación contractual entre partes de países distintos.

Así, en julio de 2001 la Comisión publicó en el Diario Oficial de la $\mathrm{CE}\left(\mathrm{N}^{\circ} 255\right.$, pág. 518) la comunicación que le envió al Consejo y al Parlamento Europeo, sobre Derecho contractual europeo (LCEur 2001\3277), en que pone de manifiesto los problemas que pueden generarse por la diversidad de ordenamientos nacionales sobre Derecho contractual. En esa comunicación, la Comisión plantea cuatro alternativas concretas: a) Entregarle al mercado la tarea de solucionar los problemas que esa diversidad genera en el tráfico económico; b) Recurrir a la elaboración de principios comunes de derecho contractual europeo mediante investigaciones conjuntas; c) Trabajar en el perfeccionamiento de la legislación comunitaria sobre contratos; o d) La adopción de un nuevo instrumento comunitario en materia de derecho contractual. En la misma publicación la Comisión solicita la colaboración de los diversos agentes

Diario Oficial de la CE $N^{\circ}$ C 158, de 26 de junio de 1989, p. 400.

Diario Oficial de la CE N ${ }^{\circ} \mathrm{C} 205$, de 25 julio de 1994, p. 518.

García (2002)

De la Mata, Almudena (2003). "Un paso más hacia la unificación del derecho privado europeo. Comunicación de la Comisión de 15 de marzo de 2003 sobre un derecho contractual europeo más coherente". Aranzadi Civil, núm. 7-8, Parte Estudio, p. 33. 
económicos y sociales "a las cuestiones fundamentales sobre la armonización del derecho contractual europeo", lo que generó importantes reacciones y valiosas respuestas que fueron consignadas luego, por la misma Comisión, en la nueva comunicación enviada al Parlamento y al Consejo, publicada el 15 de marzo de 2003 (LCEur 2003।693), sobre un Derecho contractual europeo más coherente. Como resultado del proceso consultivo de 2001, en esta última comunicación la Comisión insta por una mayor coherencia en el derecho contractual europeo y fija un plan de acción en tal sentido, planteando como métodos o herramientas de unificación la posibilidad de "consolidar, codificar y refundir" los instrumentos existentes hasta el momento, y recurrir a la creación de cláusulas contractuales tipo aplicables de modo general ${ }^{9}$.

Más recientemente, en diciembre de 2007, se llevó a cabo en la Universidad de Münster, Alemania, el Symposium académico internacional "Common Frame of Reference and Existing EC Contract Law", organizado por el Centre for European Private Law (CEP) y la Westfälische WilhelmsUniversität de Münster, en el que se plantearon las reglas comunes en este ámbito y que Schultz ${ }^{10}$ denomina como "Bases para un Marco común de Referencia para el Derecho contractual Europeo".

En segundo término, debe destacarse en esta búsqueda la tarea del Derecho internacional privado uniforme y, principalmente, el aporte significativo de la Convención de las Naciones Unidas sobre los contratos de compraventa internacional de mercaderías, también conocida como la Convención de Viena de 1980 (en adelante simplemente Convención de Viena).

La Convención, si bien se aplica en un espectro internacional que excede al de la UE, ha servido no solo como herramienta de unificación normativa en materia de compraventa internacional de mercaderías, sino también -y muy especialmente en los PECL, según veremos- como modelo de inspiración para la conformación de un Derecho privado europeo y la definición de sus principios comunes. Como lo señala el artículo 7.1. de la Convención, en efecto, el criterio base para la interpretación de sus normas radica precisamente en el carácter internacional del contrato que regula, en la necesidad de uniformar por lo mismo la aplicación de sus normas y en el deber $-\mathrm{y}$ también necesidad- de promover la buena fe en el comercio internacional; agregando luego el artículo 7.2. que todas aquellas materias no reguladas expresamente por la misma Convención deberán ser resueltas, siguiendo el mismo criterio, a la luz de los principios generales que la inspiran o, en ausencia de estos últimos, de confor-

10 Schulze, Reiner (2008). Common Frame of Reference and Existing EC Contract Law, Munich: Sellier, p. 
midad con la ley aplicable según las normas de Derecho Internacional Privado.

Finalmente, la tercera columna sobre la que se construye este Derecho privado europeo viene dada por los principios comunes que diversos grupos de estudiosos y organismos intergubernamentales de Derecho internacional han venido definiendo y sistematizando desde la década de los 80 , los que junto con reclamar el efectivo cumplimiento de las Resoluciones del PE, mencionadas más arriba, se dieron al firme propósito de estructurar en base a esos principios generales y por la vía de una labor comparativa de los distintos ordenamientos y sistemas jurídicos europeos, un cuerpo de común aplicación en todos los países miembros de la UE.

\section{(1.2) MANIFESTACIONES DOCTRINALES E INICIATIVAS DE ARMONI- ZACIÓN DE LOS PRINCIPIOS DE UN DERECHO EUROPEO DE LOS CONTRATOS}

Como cuestión previa, y según se adelantó en el párrafo precedente, si bien constituye opinión uniforme en Europa la necesidad de armonizar la normativa de los distintos Estados miembros en materia de contratos, no existe igual coincidencia entre los diversos grupos de estudio a la hora de definir el mejor camino para ello. Junto a quienes prefieren hablar de principios de un Derecho europeo de contratos, en fin, están aquellos que prefieren derechamente la opción de redactar un Código común de Derecho privado ${ }^{11}$.

Sánchez ${ }^{12}$, para graficar las diversas tendencias y criterios que existen al respecto, distingue entre aquellos autores que piensan en una unificación del Derecho privado europeo "desde arriba" (cuyo paradigma por ende sería la codificación de un Código civil europeo que elimine los derechos internos), y quienes prefieren optar por una unificación "desde abajo", entre los que a su vez distingue dos corrientes distintas: (a) Los que llama "academicistas", que piensan en una unificación que refiere al antiguo ius commune, propio de la integración del Derecho romanocanónico, poniendo así el énfasis en una ciencia jurídica y doctrinas compartidas o, en otros términos, en la existencia de un pensamiento jurídico común que surge de tradiciones e historias únicas; y (b) Los que conciben

11 Para Schultze, las diferencias que se observan entre estos grupos de estudiosos radican principalmente, como se dijo, en que algunos apuntan su labor a la formulación de principios de derecho contractual europeo, como el grupo del profesor danés Ole Lando y el denominado "Study Group on European Civil Code"; mientras que otros pretenden desarrollar un texto normativo de aplicación directa, ya sea en forma de ley, ley modelo o contratos modelo. Entre estos últimos, el Grupo de Pavia en Italia, coordinado por el profesor Giuseppe Gandolfi, ha redactado incluso un anteproyecto de Código Civil Europeo, al que se le critica -sin embargo- tener una marcada influencia del Código civil italiano. Schultze (2003) 632.

12 Sánchez Lorenzo, Sixto A. (2002). "Derecho Privado europeo". Estudios de Derecho Privado Europeo, $\mathrm{N}^{\circ} 2$, p. 142. 
el Derecho privado europeo como el resultado de un estudio comparado de los distintos ordenamientos internos y que comprende, por lo mismo, no solo los aspectos comunes sino también las diferencias que indudablemente existen entre ellos, incluso a nivel sistémico, poniendo ahora el énfasis en los principios generales que resultan comunes. Para Sánchez, en fin, quienes postulan la unificación "desde abajo", en sus dos vertientes, proponen no la destrucción o suplantación de los ordenamientos internos por uno europeo o supranacional (Código civil europeo), sino la "deconstrucción” del Derecho privado que, partiendo por respetar y reconocer el Derecho comunitario y el Derecho privado interno de cada país, vaya paulatinamente convergiendo en un Derecho privado europeo mediante "técnicas o fuentes blandas". Se habla así de un Derecho privado europeo positivo "desde abajo" o de una codificación soft, al estilo norteamericano de restatements (soft law), donde se insertan precisamente los PECL según se señala en su artículo $1101^{13}$.

Curiosamente, sin embargo, en su exposición de principios los propios PECL seńalan que estos pueden ser tenidos por los órganos de la UE como fuente o base para una futura codificación (Introduction, xxiii ${ }^{14}$ ), lo que lleva a pensar finalmente en la existencia de una idea compartida de codificación, aunque con distinta concepción y contenido.

No nos detendremos a analizar aquí los argumentos a favor o en contra de una u otra alternativa, pues ello escapa a la materia de nuestra investigación. Únicamente, destacaremos a continuación las principales iniciativas doctrinales tendientes a definir y sistematizar los principios que informan el Derecho europeo de los contratos:

\section{(1.2.1) Principios de Derecho mercantil internacional según Unidroit}

El Instituto Internacional para la Unificación del Derecho Privado -UNIDROIT-, organización independiente con sede en Roma, ha reunido y confeccionado los denominados "Principles of Internacional Comercial Contracts", publicados en el ańo $1994^{15}$, y que constituyen el resultado de más de quince años de trabajo de un grupo de investigadores, académicos, abogados especialistas, jueces y servidores públicos de otros treinta países. La importancia de esta labor de recopilación radica básicamente en que por ella se establece un cuerpo armónico de reglas a las que pueden recurrir voluntariamente las partes contratantes de todo

SÁNCHEZ LoRENZO (2002) 142-143.

Vid. infra, nota 20.

Unidroit publicó una segunda versión de los Principios, en abril de 2004, agregando a los siete capítulos originales otros tres nuevos (capítulos $8^{\circ}, 9^{\circ}$ y $10^{\circ}$ ), que tratan entre otros temas relevantes sobre la asignación de riesgos, transferencia de obligaciones y reglas sobre contratos, abordando así dificultades prácticas que el texto original no contemplaba. 
el mundo, sin importar las diferencias normativas y de tradición jurídica que puedan existir entre ellas, ni las condiciones económicas y sociales que puedan presentar los países en que esas reglas serán aplicadas, según el caso.

\section{(1.2.2) Los grupos de trabajo para la armonización del Derecho con- tractual europeo}

Diversos son los grupos de estudio integrados por investigadores, académicos y abogados especialistas que se han dedicado también en Europa a esta tarea, resultando de ello distintas publicaciones y trabajos que, quizá con objetivos instrumentalmente distintos según se dijo más arriba, han procurado avanzar en un mismo camino de armonización.

Entre estos grupos" ${ }^{16}$ está la denominada "Comisión para el Derecho Europeo de Contratos" o Grupo Lando (en honor a su fundador y primer presidente, Ole Lando), creado en 1980 y que ha tenido un carácter más académico que oficial. En cuanto a su funcionamiento, la doctrina distingue entre la primera Comisión, que abarca un periodo entre 1980 y 1991 y que muestra entre sus resultados los ya mencionados Principios de Derecho Contractual Europeo, Partes I y II, sobre principios generales de derecho contractual y obligaciones; y la segunda Comisión, entre los años 1992 y 1996, con los Principios de Derecho Contractual Europeo, Parte III, sobre otros aspectos relacionados como la prescripción, la compensación y la cesión del contrato ${ }^{17}$. Los objetivos esenciales de estos principios pueden sintetizarse en (a) la necesidad de facilitar el comercio transfronterizo en la UE y reforzar el mercado único; (b) la creación para ello de un sustrato jurídico comunitario básico en materia de Derecho de contratos, que no haga distinción entre contratos mercantiles y civiles-como ocurre

16 Otros grupos que estudian el Derecho contractual europeo son "The Common Core of Private Law in Europe" o "Grupo de Trento"; "The Tilburg Group on Torts"; "Study Group for a European Civil Code"; el denominado "Study Group on European Civil Code", mencionado ya en la nota 11 anterior, que a comienzos del ańo 2008 publicó una edición provisional de los denominados Principles, Definitions and Model Rules of European Private Law. Draft Common Frame of Reference (DCFR); y el Acquis Group (http://acquis.jura.uni-bielefeld.de), al que corresponden los denominados Aquis Principles o ACQP, cuyo Capítulo 8, incluido en la obra de Schultze (2008), contiene las reglas relativas a los remedios (Remedies) para el caso de incumplimiento contractual y las de indemnización por dańos. El mismo grupo de estudio publicó en 2007 la obra denominada Acquis Group, Principles of Existing EC Contract Law -Contract I- Pre-contractual Obligations, Conclusión of Contract, Unfair Terms Principles of the Existing EC Contract Law (Acquis Principles, capitulos 1 al 7).

17 Díez-Picazo, L. / Roca Trías, E. / Morales, A. (2002). Los Principios del derecho europeo de los contratos, Madrid: Civitas, p. 76. Otros autores, sin embargo, distinguen tres Comisiones distintas: La primera, que publicó en 1995 la obra "Principles of European Contract Law, Part I: Performance. Non-performance and Remedies"; la segunda, que publicó en 1999 la obra "Principles of European Contract Law, Part I y Part II"; y una tercera Comisión, que se ocupa de la preparación de una tercera parte de los Principios. Al respecto García (2002). 
en cambio con los Principios de Unidroit- o entre contratos en general y contratos de consumidores; (c) eliminar-como consecuencia de lo anterior- los obstáculos que plantean las diferencias normativas entre los países miembros, reduciendo así los costes de esa contratación; y (d) la creación de un puente entre el civil law el common law, por la vía de destacar las similitudes entre ambos sistemas y no sus diferencias ${ }^{18}$.

En síntesis, y siguiendo tal vez el ejemplo de los restatemenst norteamericanos, de probada eficacia por cierto, los PECL no buscan transformarse en modo alguno en norma imperativa para las partes contratantes, sino simplemente servir de orientación para las partes y eventualmente para el juez en caso de conflicto ${ }^{19}$.

\section{2) EL INCUMPLIMIENTO ESENCIAL COMO PRINCIPIO DE DERECHO CONTRACTUAL EUROPEO}

Hemos dicho antes que los PECL, partes I y II, son el fruto del trabajo desarrollado por la Comisión Lando entre los años 1980 y 1991, y refunden los principios generales en materias de Derecho de los contratos y obligaciones.

En el capítulo VIII, artículos 8101. y siguientes, bajo el epígrafe "Incumplimiento y acciones en general", los PECL tratan de modo general la figura del incumplimiento del contrato, distinguiendo al respecto, claramente, el incumplimiento que tiene el carácter de esencial del que no lo tiene. Sus consecuencias, a su turno, se regulan en el Capítulo IX de los PECL, como lo seńala expresamente el artículo 8101. (1), reconociéndose allí la facultad del acreedor de resolver directamente el contrato, previa notificación a la otra parte ${ }^{20}$.

18 Díez-Picazo, L. / Roca Trías, E. / Morales, A. (2002) 77 y 85.

19 Los Restatements of the Law of Contract son recopilaciones de los principios fundamentales y comunes imperantes en las distintos estados de los Estados Unidos de Norteamérica, sobre determinadas materias de Derecho civil y Derecho mercantil, realizadas por el "American Law Institute", que persiguen básicamente servir como pautas a seguir en la dictación de sus sentencias por los tribunales norteamericanos en general. Los restatements se nutren al mismo tiempo de esa misma jurisprudencia y de las soluciones prácticas que se ha dado a determinados asuntos. Sin embargo, y como apunta Sánchez, los PECL van incluso más allá que los restatements, por cuanto aquellos tratan de crear -a diferencia de estos últimos- una realidad jurídica nueva y distinta, partiendo -y en esto sí coinciden- del estudio comparado de los diversos ordenamientos. En esto último a Sánchez (2002) 309.

Para el análisis de estos capítulos se ha tomado como base la obra Principles of European Contractual Law - Parts I and II, preparado por Lando, O. I Beale, H. (2000). Principles of European Contract Law, Parts I and II, The Hague: Kluwer Law International, su traducción al espańol puede encontrarse en Díez-Picazo, L. / Roca Trías, E. / Morales, A. (2002) 61 . 
Lo anterior no debe llevar a pensar que los PECL contemplan una concepción compleja del incumplimiento. Por el contrario, para estos todo incumplimiento puede originar, como veremos, la resolución del contrato, ya sea que este derive del retraso del deudor en su cumplimiento o de la inobservancia de la obligación misma (art. 9301.); pero en este último caso, la entidad del incumplimiento debe revestir el carácter de esencial si hablamos de la resolución como remedio (condition, en la terminología inglesa).

De esta forma entonces, la facultad de resolver el contrato por incumplimiento se reserva solo para los casos en que este es esencial, en cuanto figura que apunta a la tutela de los derechos e intereses del acreedor, pero también del deudor. Dicho en otros términos, los PECL facultan por cierto al acreedor para resolver un contrato incumplido por su deudor, con más la indemnización de los perjuicios causados; pero al mismo tiempo contemplan algunas restricciones en el ejercicio de este derecho-que se ejerce extrajudicialmente por lo demás-, con miras a evitarle al deudor perjuicios innecesarios ${ }^{21}$. Se trata, como apunta Vázquez ${ }^{22}$ al comentar el artículo 25 de la Convención de Viena, de "favorecer la conservación de los contratos, como un 'bien inmaterial' generador de riqueza".

\section{(2.1) CONCEPTO Y ELEMENTOS DEL INCUMPLIMIENTO ESENCIAL}

Según el artículo 8103, el incumplimiento esencial se define de la siguiente forma:

"Art. 8103. Incumplimiento esencial.

El incumplimiento de una obligación es esencial si:

a) la estricta observancia de la obligación forma parte de la esencia del contrato; 0

b) el incumplimiento priva sustancialmente a la parte perjudicada de aquello que tenía derecho a esperar de acuerdo con el contrato, a menos que la otra parte no haya previsto y no haya podido prever razonablemente tal resultado; 0

c) el incumplimiento es intencional y da a la parte lesionada razones para creer que no puede confiar en el cumplimiento futuro de la otra parte".

21 En cuanto a la forma de ejercer la facultad de resolver el contrato, los PECL recogen el sistema propio del common law y de algunos ordenamientos como el portugués (art. $436 \mathrm{I}$ del Código Civil), en que la resolución opera directamente, previa notificación al deudor y sin necesidad de sentencia judicial previa, como ocurre en cambio con el sistema de Derecho civil francés (art. 1.184 del Código Civil) y los ordenamientos inspirados en él. Entre ambos sistemas se encuentra por ejemplo el holandés, que permite resolver un contrato judicial o extrajudicialmente, según elección del acreedor (art. 6.267 del Código holandés).

22 VÁzquez LépinetTe, Tomás (2000). "Compraventa Internacional de Mercaderías. Una visión Jurisprudencial”. Derecho Patrimonial, N 2, p. 162. 
Según esta disposición, el incumplimiento se considera esencial y faculta por ende al acreedor para notificar la resolución del contrato, en los casos siguientes:

\section{(2.1.1) Estricto cumplimiento de la obligación}

Como lo señalan los comentarios que acompańan el texto de los PECL, en el primer caso (estricta observancia de la obligación como esencia del contrato) no se apunta a la gravedad de la infracción propiamente tal, sino a la necesidad primordial que tiene el acreedor en orden a que el deudor cumpla estrictamente lo acordado. De esta forma, cualquier desviación del deudor en el cumplimiento de la obligación pactada, autorizará al acreedor para desligarse de las obligaciones correlativas que le impone el contrato ${ }^{23}$.

En consecuencia, según esta primera figura de incumplimiento esencial no debe atenderse a la gravedad del incumplimiento o de sus consecuencias, sino a la circunstancia de que las partes han optado explícitamente por resolver el contrato en caso de incumplimiento (sujetando el contrato a una condición resolutoria), o implícitamente si así se desprende de manera inequívoca del mismo contrato (v. gr., cuando la calidad o cantidad de la cosa comprada debe reunir "necesariamente" determinadas características o cierto número, respectivamente). Para ello, en fin, el contrato debe estar redactado de tal forma que el incumplimiento de una de las partes permita a la otra terminar o resolver el contrato, según su naturaleza.

Sin embargo, y como lo seńalan las notas a los PECL, incluso a falta de estipulaciones expresas de las partes las consecuencias apuntadas podrían desprenderse de las circunstancias que rodean el otorgamiento del contrato, de las normas y principios jurídicos comunes aplicables en un caso determinado ${ }^{24}$, de los usos y costumbres mercantiles o del curso o aplicación práctica que las partes hayan dado a sus relaciones comerciales.

\section{(2.1.2) Gravedad de las consecuencias del incumplimiento para el acreedor}

Este segundo supuesto de incumplimiento esencial está tomado, casi textualmente en partes, del artículo 25 de la Convención de Viena, que señala:

Lando, O. / Beale, H. (2000) 364.

En la mayoría de los ordenamientos, por ejemplo, la entrega oportuna de las mercaderías o de los documentos representativos del dominio de las mercancías en la compraventa mercantil, constituyen elementos esenciales del contrato. 
"Articulo 25. El incumplimiento del contrato por una de las partes será esencial cuando cause a la otra parte un perjuicio tal que la prive sustancialmente de lo que tenía derecho a esperar en virtud del contrato, salvo que la parte que haya incumplido no hubiera previsto tal resultado y que una persona razonable de la misma condición no lo hubiera previsto en igual situación".

Según esto entonces, y a diferencia del primer caso, la segunda forma de incumplimiento esencial presupone necesariamente una valoración de las consecuencias que el incumplimiento le acarrea al acreedor. $\mathrm{Si}$ ellas son de tal entidad que le privan del beneficio que esperaba o tenía derecho de esperar en virtud del contrato, tendrá derecho a resolver el contrato aun cuando este no haya contemplado expresamente esa consecuencia para el caso de infracción. Con todo, cabe advertir que la disposición transcrita no especifica-como tampoco lo hace el artículo 25 de la Convención de Viena- si esa frustración en los resultados esperados debe apreciarse con un criterio subjetivo (esto es, apuntando al interés que tenía el acreedor en el cumplimiento) o, por el contrario, objetivo (esto es, considerando el objeto del contrato en cuanto tal y las circunstancias concurrentes).

A modo de ejemplo, los comentarios a los PECL mencionan el caso de un contrato en que la parte A encomienda a B la construcción de cinco estacionamientos de carga y descarga para su almacén (garajes) y la construcción y pavimentación del camino aledańo, con el compromiso de entregar las obras antes del 1 de octubre en que abre ese almacén al público. El 1 de octubre los cinco garajes están construidos, al igual que el camino aunque sin pavimentar, lo que impide utilizar los garajes. El incumplimiento en tal caso ha sido esencial. Como contrapartida, si el camino así construido -aunque no pavimentado- es lo suficientemente liso y compacto para permitir el acceso de los camiones de A hacia los estacionamientos, y $\mathrm{B}$ lo pavimenta en fecha muy próxima al 1 de octubre, el incumplimiento no es esencial ${ }^{25}$.

Del mismo modo, en la especie no se atiende solo a la conducta del deudor que incumple, sino también ha de observarse el proceder del acreedor y su disposición a reducir las consecuencias dańosas del incumplimiento. En otros términos, si esas consecuencias han sido producidas por su propia inacción, no habrá derecho a resolver el contrato por no tratarse de un incumplimiento esencial.

Por último, el propio artículo 8103. (b) faculta al deudor para evitar en su caso la resolución por incumplimiento, cuando los resultados de dicho incumplimiento no han podido ser previstos razonablemente 
por aquel. Para ello, y como lo seńalan los comentarios a los PECL, deberá tomarse como base la conducta de una persona situada en la misma posición del contratante incumplidor, utilizando una medida razonable de dirigencia y cuidado. La interrogante que queda pendiente, sin embargo, consiste en determinar el momento que debe tenerse en cuenta para definir si esos efectos pudieron ser previsibles o no para el deudor: ¿Al momento de celebración del contrato?; ¿al momento de celebración y también durante la ejecución del contrato? Nos parece que la solución debe ser esta última.

Desde luego, el deudor debe extremar en todo caso su celo y cuidado en el estricto cumplimiento de sus obligaciones. Por lo mismo, si durante la ejecución del contrato el deudor toma conocimiento de un hecho o circunstancia cuya ocurrencia o no -según sea el caso concreto- constituye un aspecto determinante para el acreedor y lo que este espera del contrato, no puede entenderse luego que aquel no estuvo en condiciones de prever razonablemente los resultados del incumplimiento. Por cierto, esos hechos o circunstancias deben formar parte de la obligación estipulada o derivar de la misma en cuanto manifestación del principio de la buena fe en el cumplimiento de las obligaciones. Para explicar lo dicho, analicemos el ejemplo que se da sobre este segundo criterio de incumplimiento esencial en los comentarios a los PECL:

A encomienda a $\mathrm{B}$ la instalación de un sistema de calefacción central para su casa habitación, de manera que la temperatura se mantenga estable en $\operatorname{los} 20^{\circ} \mathrm{C}$. Sin saberlo B, una de las habitaciones de la casa de A está destinada al cultivo de plantas exóticas que demoran muchos ańos en desarrollarse, y que no pueden subsistir a temperaturas inferiores a los $20^{\circ}$ C. Por una falla inesperada de las tuberías de calefacción de esa habitación en particular, la temperatura baja $2^{\circ} \mathrm{C}$ y las plantas mueren, perdiéndose años de trabajo ${ }^{26}$.

En este caso, el incumplimiento de B no es esencial pues, ciertamente, no estuvo en condiciones de prever las consecuencias que tendría para A una baja momentánea de $2^{\circ} \mathrm{C}$ en una de las dependencias de una casa destinada a la habitación. Ahora bien, si durante la ejecución del contrato $\mathrm{B}$ hubiese tomado conocimiento de esa circunstancia, nos parece que la solución sería precisamente la inversa, incurriendo por ende en incumplimiento esencial.

Advirtamos, en todo caso, que no es esta la solución que plantean algunos autores en punto al artículo 25 de la Convención de Viena ${ }^{27}$. 


\section{(2.1.3) Incumplimiento intencional}

El tercer supuesto de incumplimiento esencial lo constituye el caso en que el deudor ha tenido la intención de incumplir, lo que deriva en la pérdida de confianza del acreedor respecto del cumplimiento futuro de la obligación (sin perjuicio de las disposiciones que facultan para resolver el contrato en caso de retardo).

En este caso puede ser que el incumplimiento no sea aun esencial o que el deudor se encuentre dentro de los plazos estipulados para su cumplimiento; pero es la conducta de este deudor la que lleva a creer que la obligación no será cumplida según lo acordado. En efecto, y como apuntan Díez-Picazo, Roca y Morales, esta situación se aplica a aquellas relaciones contractuales en que existen obligaciones que deberán ser cumplidas todavía en el futuro ${ }^{28}$; y agreguemos nosotros que también lo es respecto de obligaciones que se están ejecutando.

Esta figura apunta en consecuencia a resguardar los intereses del acreedor cuando por un hecho intencional del deudor, la pérdida de confianza en ese cumplimiento futuro resulta debidamente justificada. En otros términos, y como lo seńalan los comentarios a los PECL, la intencionalidad que determina el curso volitivo de la conducta del deudor en estos casos permite que un incumplimiento que en sí mismo no es necesariamente esencial, sea considerado como tal en el marco de las obligaciones futuras surgidas del mismo contrato. Así por ejemplo:

A encomienda a B la construcción de un Supermercado, especificando una determinada calidad de ladrillos. Durante la construcción, B opta por usar ladrillos de inferior calidad en aquellas partes de la construcción que sea difícil de detectar. No obstante, A constata la situación anterior y B, ante ello, se allana a remover los ladrillos y reponerlos por otros de la calidad especificada. Si bien el incumplimiento no es esencial según los criterios antes estudiados, la pérdida de confianza justificada de A permite darle ese carácter y resolver el contrato anticipadamente ${ }^{29}$.

\section{(2.2) INCUMPLIMIENTO ESENCIAL PREVISIBLE Y MEDIDAS PREVENTIVAS}

Los artículos 9304 y 8105 de los PECL señalan:

\section{"Art. 9304. Incumplimiento anticipado.}

Cuando antes del momento de cumplimiento por una de las partes, resulta evidente que existirá un incumplimiento esencial, la otra parte podrá resolver el contrato". 
"Art. 8105. Garantía de cumplimiento.

1) La parte que razonablemente crea que se producirá un incumplimiento esencial de la otra parte, puede exigir una garantía adecuada del cumplimiento debido y, mientras tanto, puede suspender el cumplimiento de sus propias obligaciones, durante todo el tiempo que se mantenga su creencia razonable".

2) Si tal garantía no se adopta dentro de un plazo razonable, la parte que la exige puede dar por terminado el contrato si sigue creyendo razonablemente que se producirá un incumplimiento esencial de la otra parte y notifica a resolución sin demora".

Los artículos recién citados, nuevamente, recogen lo dispuesto por el artículo 72 de la Convención de Viena y, también, en el artículo 7.3.3. de los Principios Unidroit ya mencionados. Aunque ambos artículos se complementan entre sí, para facilitar su análisis los veremos separadamente:

\section{(2.2.1) Caso del artículo 9304.: resolución del contrato}

Según esta disposición, los PECL - al igual que la Convención de Viena y los Principios Unidroit- recogen lo que en el derecho anglosajón de denomina anticipatory non-performance, y que permite al acreedor resolver el contrato como si el incumplimiento fuese actual (o actual nonperformance), en el entendido que este no puede quedar vinculado por un contrato cuando se ha hecho evidente que la otra parte no lo cumplirá.

Desde luego, la figura que comentamos presupone que el incumplimiento del contrato - en todo caso esencial- debe ser evidente (o "patente", en la terminología de la Convención de Viena), esto es, que necesariamente vaya a ocurrir sin necesidad de esperar a que ello se consume materialmente. Por lo anterior, la facultad de resolver el contrato que se le reconoce aquí al acreedor presupone, a su turno, la anticipación o caducidad de un plazo que favorece al deudor, lo que hace dudoso por tanto que estemos efectivamente ante un incumplimiento y resolución anticipados.

\section{(2.2.2) Caso del artículo 8105: garantía de cumplimiento y suspensión}

Sin perjuicio de la facultad que concede el artículo 9304, y como alternativa previa a la resolución del contrato, el artículo 8105 arriba transcrito permite al acreedor que crea razonablemente que ocurrirá un incumplimiento esencial, exigir la constitución de una garantía del cumplimiento $y$, entretanto, suspender el cumplimiento de sus obligaciones correlativas e conformidad al artículo 9201. Si esa garantía no es otorgada en un plazo razonable, el acreedor podrá resolver el contrato, comunicándoselo sin retraso al deudor. 
De manera entonces que ante un incumplimiento esencial previsible el acreedor tiene los siguientes cursos de acción:

(a) Solicitar al deudor la constitución de una garantía si razonablemente cree que se producirá un incumplimiento, suspendiendo entretanto el cumplimiento de sus obligaciones (art. 8105);

(b) Comunicar derechamente la resolución del contrato cuando el incumplimiento sea evidente o patente.

¿Pero puede el acreedor optar libremente entre una y otra alternativa? En esta parte la doctrina ofrece distintas soluciones. A modo de ejemplo, para Díez-Picazo, Roca y Morales el acreedor puede optar libremente por cualquiera de los caminos seńalados; aunque corre el riesgo de que el uso del segundo (esto es, la resolución) pueda resultar injustificado si el deudor demuestra luego que hubiese podido cumplir ${ }^{30}$. En cambio, para Andreu ${ }^{31}$ el acreedor está obligado a recurrir a la primera de las alternativas planteadas (garantía y suspensión provisional) cuando solo le asiste una "duda razonable" de que se producirá luego el incumplimiento; reservando la facultad de resolver el contrato para los casos en que ese incumplimiento se hace "evidente" o "patente". A mi modo de ver, la solución debe ser esta última pues, claramente, la utilización de las expresiones "evidente" y/o "patente" no son puramente casuales y denotan, por el contrario, la necesidad de que concurran elementos objetivos que vayan más allá de la simple "duda razonable" - por ende subjetiva- a que se refiere el artículo 8105.

\section{3) El incumplimiento esencial a la LuZ del Código Civil CHI- LENO. SÍNTESIS COMPARADA}

Finalmente, me ocuparé de hacer una breve reseńa comparada de los PECL y del instituto del incumplimiento esencial que se ha venido desarrollando, teniendo a la vista las normas sobre incumplimiento contenidas en el Código Civil chileno.

\section{(3.1) EN CUANTO AL PRIMER CRITERIO: ART. 8103. (A)}

En primer término, la estricta observancia de la obligación, como parte esencial del contrato [art. 8103. (a) PECL], se encuentra recogida

\footnotetext{
30 Díez-Picazo, L. / Roca Trías, E. / Morales, A. (2002) 355.

31 Andreu Martínez, Belén (2003). "Incumplimiento anticipado; regulación en los Principios de Derecho Contractual Europeo y soluciones a la vista del Código civil español", en Espiau Espiau, Santiago / Vaquer Aloy, Antoni (Coords), Bases de un Derecho contractual europeo, Valencia: Tirant lo Blanch, p. 334.
} 
en diversas disposiciones del Código Civil y deriva, desde luego, del principio de cumplimiento estricto de las obligaciones contractuales - pacta sunt servanda-contenido en el artículo 1545 de dicho cuerpo legal. Así se desprende de los artículos 1479, 1487 y 1489 del Código Civil, para aquellos casos en que las partes estipulan expresamente que el incumplimiento de una obligación determinada acarreará la resolución del contrato; y así aparece además en el artículo 1489 del mismo Código, en cuya virtud todo contrato bilateral lleva implícita la condición resolutoria de no cumplirse por alguna de las partes lo pactado.

\section{(3.2) EN CUANTO AL SEGUNDO CRITERIO: ART. 8103. (B)}

Las dificultades comienzan sin embargo con el segundo criterio de incumplimiento esencial contenido en los PECL, art. 8103 (b).

En efecto, no existen en el Código Civil chileno normas semejantes a la recién mencionada o al artículo 25 de la Convención de Viena, que descarten explícitamente la posibilidad de resolver el contrato cuando el incumplimiento del deudor, no obstante haberse producido efectivamente, no priva al acreedor de lo que este esperaba o tenía derecho a esperar en virtud del mismo.

Con todo, lo anterior no quiere decir en modo alguno que en nuestro sistema todo y cualquier incumplimiento da lugar o deriva necesariamente en la resolución del contrato, por inocuo que pueda ser. Por el contrario, y siguiendo aquí el modelo francés, el Código civil chileno exige la previa intervención del tribunal de justicia competente para declarar resuelto un contrato por incumplimiento (a menos que se trate de una condición resolutoria expresa), lo que trasunta el interés del legislador en cuanto a que solo el incumplimiento grave, debidamente constatado por el juez, justifique la destrucción del contrato. Del mismo modo, por regla general la acción de resolución puede enervarse por el deudor durante el curso del juicio, cumpliendo; y ello evidencia también un propósito de preservar el contrato, y no al revés.

Sin embargo, la jurisprudencia mayoritaria en esta materia, tomando como base las normas sobre indivisibilidad del pago e integridad de la prestación (artículos 1569 y 1591 inc. $2^{\circ}$ del Código Civil, respectivamente), ha insistido en la exigibilidad total de la obligación y, por ende, en la resolución del contrato como remedio ante su incumplimiento total o parcial, lo que a nuestro entender puede resultar exagerado en determinadas circunstancias. No obstante, fallos más recientes permiten confiar en un cambio paulatino del rumbo en esta materia, de manera de incorporar como criterio de análisis jurisdiccional la necesaria proporcionalidad que debe existir entre el incumplimiento y sus efectos. La entidad o cuantía del incumplimiento, en fin, no es ni puede ser en modo alguno un factor irrelevante al momento de decidir sobre sus consecuencias en el contrato. 
Así por ejemplo, en un interesante fallo de casación la Corte Suprema dio especial relevancia al factor recién apuntado, considerándolo incluso determinante para rechazar un recurso de casación en el fondo fundado -en lo que aquí interesa- en la supuesta infracción de las normas que regulan la excepción de incumplimiento parcial de contrato o exceptio non rite adimpleti contactus. En efecto, y no obstante que la excepción opuesta en esa causa por el recurrente no buscaba enervar obviamente una acción de resolución del contrato respectivo, sino de cumplimiento, los fundamentos esgrimidos en ese fallo inciden en el mismo problema que aquí hemos planteado, solo que con distinto escenario. Dijo al respecto la Corte:

"470.- Que para que esta excepción resulte atendible ...es necesario que la inejecución atribuida al acreedor que demanda en el juicio incida en una obligación que tenga asignada una real trascendencia en el contrato. Por consiguiente, no puede esgrimirse como basamento de ella la falta de cumplimiento de una obligación que, en el ámbito de los compromisos pactados por las partes, revista una significación jurídica menor.

La fundamentación de este medio de defensa en una inejecución de escasa entidad puede atentar contra un principio rector en la ejecución de los contratos, como es la buena fe.

Acerca de este punto se ha dicho que: "...no podría admitirse la excusa válida de incumplimiento ante defectos $u$ omisiones irrisorias, inocuas o intrascendentes que no deben tener repercusión juridica. Antes bien, revelarian un afán de lucro ilícito y aun dolo, de parte de aquel que quisiera valerse de estos verdaderos pretextos. Si en este punto no se obra con cautela y mesura, fácil sería llegar a una puerta ancha que diera entrada al aprovechamiento doloso en una materia que está precisamente formulada en el campo de la excepcionalidad y de la riqueza de valores jurídicos del más alto nivel" (Fernando Fueyo Laneri. "Cumplimiento e incumplimiento de las Obligaciones"; página 235. Editorial Juridica. Santiago de Chile. 1991)"32.

Este criterio, entonces, que como advierte luego el propio fallo es compartido por otros autores nacionales ${ }^{33}$, desconoce toda relevancia al incumplimiento intrascendente o de menor entidad como fundamento de la excepción de incumplimiento parcial del contrato. Por lo mismo, y de aplicarse igual razonamiento a la resolución como consecuencia del incumplimiento, deberíamos concluir que esta tampoco resulta proce-

Corte Suprema, 31 de marzo de 2003, Rol N ${ }^{\circ}$ 1594-2001, Incomin con ENAMI, juicio arbitral, casación en el fondo, indemnización de perjuicios.

33 López Santa María, Jorge (1986). Los Contratos (Parte General), Santiago: Editorial Jurídica de Chile, p. 845. 
dente cuando el hecho u omisión constitutivos de incumplimiento son de rango exiguo o menor, considerando las circunstancias del caso y lo que el acreedor esperaba o tenía derecho a esperar. Entenderlo de otro modo nos lleva necesariamente a discriminar de manera injustificada respecto de los efectos jurídicos de un mismo fenómeno (el incumplimiento), según cuál sea en definitiva la acción por la que opta el acreedor (cumplimiento o resolución).

\section{(3.3) EN CUANTO AL TERCER CRITERIO: ART. 8103. (C)}

En lo que concierne al incumplimiento intencional a que se refiere el artículo 8103. (c), me parece que tal figura puede incluirse perfectamente en la que contempla por su parte el artículo 44 inciso final del Código Civil chileno, en relación con el artículo 1558 del mismo Código y que atiende a los efectos del incumplimiento doloso del contrato.

Desde luego, al hablar los PECL de incumplimiento intencional quedan fuera todas aquellas figuras de incumplimiento culpable o negligente, lo que hace innecesario referirnos aquí a la concepción tripartita de la culpa que al respecto contempla nuestro ordenamiento positivo. Se trata, en consecuencia, de la conducta consciente del deudor que durante la ejecución del contrato y a sabiendas del daño que le ocasionará al acreedor, opta por incumplir sus obligaciones con miras a obtener un beneficio, lo que dará en todo caso lugar a la resolución del contrato cuando tal intención se acredita debidamente.

En lo que no parece existir coincidencia, sin embargo, es en la equiparación que de la culpa grave y el dolo se hace en el artículo 44 inciso $2^{\circ}$ ya citado, lo que no parece posible a la vista del criterio de incumplimiento que comentamos. En efecto, y si bien la equiparación de que trata la norma precitada no es conceptual sino solo de efectos, los diversos tratamientos normativos que sobre esta materia se contienen en los Códigos europeos no permiten encontrar una solución única y de general aplicación a este problema. Así por ejemplo, los artículos 1102 del Código Civil español y 276 del Código Civil alemán, respectivamente, sancionan el dolo con la nulidad, pero nada dicen de la culpa grave; a diferencia del Código suizo de las obligaciones (art. 100) o el Código Civil griego (art. 332.1), que optan por la solución inversa. Por lo anterior, la equiparación que comentamos, amén de no estar mencionada siquiera en los PECL, resulta inconciliable con su orientación y fines de uniformidad basada en principios comunes. $\mathrm{Al}$ respecto nos remitimos a lo dicho supra ${ }^{34}$. go: Editorial Jurídica de Chile, p. 436. 


\section{(3.4) RESOLUCIÓN ANTICIPADA DEL CONTRATO E INCUMPLIMIENTO PREVISIBLE: ART. 9304}

Por otra parte, la resolución anticipada del contrato por incumplimiento esencial previsible, en los términos del artículo 9304, encuentra en el Código Civil chileno un importante obstáculo: En tanto la obligación del deudor no sea exigible, no puede considerarse que haya incurrido en incumplimiento del contrato. Así se desprende de los artículos 1538, 1557 y 1551 del Código Civil, distinguiéndose en este último, además, casos en que la exigibilidad de la obligación coincide con la mora del deudor (art. $1551 \mathrm{~N}^{\circ} 1$ ) y aquellos que requieren interpelación del acreedor para constituir al deudor en mora. Más aún, esta distinción entre mora y exigibilidad no se contempla siquiera en los PECL, al igual que en la Convención de Viena de 1980.

Por lo dicho entonces, en el Código Civil chileno no resulta posible recurrir a la resolución del contrato cuando el incumplimiento es previsi$b l e$, a menos que esa previsibilidad se traduzca en la anticipación del plazo que favorece al deudor, en los términos del artículo 1496 del Código Civil; pero como hemos dicho antes, no estaremos aquí ante una resolución anticipada por incumplimiento, sino de caducidad o vencimiento anticipado del plazo estipulado.

Las mismas diferencias se observan en el Código Civil español, que por regla general tampoco permite considerar como incumplidora a la parte cuya obligación no es aun exigible (artículos 1124, 1125 y 1127). Al igual que en el Código Civil chileno, en fin, en estos casos debe recurrirse previamente a la anticipación del plazo que favorece al deudor, en cuanto único camino para acceder a los remedios establecidos frente a ese incumplimiento (artículo 1129, de muy similar redacción al artículo 1496 del Código Civil chileno).

\section{(3.5) EN CUANTO A LA GARANTÍA DE CUMPLIMIENTO Y SUSPENSIÓN DE OBLIGACIONES CORRELATIVAS; ART. 8105. (1)}

Por último, digamos que la facultad del acreedor para exigir garantía de cumplimiento al deudor y suspender entretanto el cumplimiento de sus obligaciones, reconocida en el artículo 8105. (1) de los PECL en tanto se mantenga la "creencia razonable" de un incumplimiento futuro, no encuentra tampoco correlato en nuestro Código Civil como regla general.

Según el artículo 1552, pues, en un escenario como el propuesto por los PECL el acreedor se encontraría impedido de demandar el cumplimiento o la resolución del contrato bilateral, por incumplimiento de su contraparte, a menos que ese acreedor haya cumplido a su vez con sus obligaciones o se encuentre llano a cumplirlas. En otros términos, para demandar el cumplimiento o la resolución del contrato el acreedor debe 
haber cumplido o haber dado principio de ejecución a sus obligaciones, pues de lo contrario el deudor no se encontrará en mora de cumplir las suyas (exceptio non adimpleti contractus).

Sin embargo, en determinados supuestos concretos $-\mathrm{y}$ por ende excepcionales-, el Código Civil contempla soluciones similares a los que entregan los PECL:

(a) Así por ejemplo, en el contrato de compraventa la ley autoriza al acreedor-vendedor- para suspender precisamente el cumplimiento de su obligación -entregar la cosa vendida- si la fortuna del deudor-comprador- ha menguado considerablemente después del contrato. En tales casos, el artículo 1826 inciso segundo del Código Civil permite, al igual que el artículo 8105.(1) de los PECL, suspender la entrega de la cosa hasta tanto se verifique el pago o se lo garantice de manera suficiente. Dice el artículo 1826 inc. $2^{\circ}$ :

"...Pero si después del contrato hubiere menguado considerablemente la fortuna del comprador, de modo que el vendedor se halle en peligro inminente de perder el precio, no se podrá exigir la entrega aunque se haya estipulado plazo para el pago del precio, sino pagando, o asegurando el pago".

En otros términos, y a menos que se le pague efectivamente o se le asegure el pago, la ley le reconoce aquí al vendedor la facultad de suspender el cumplimiento de su obligación cuando existe un peligro fundado de perder no solo el precio de la cosa, sino también esta última si fuese entregada. Norma similar se contiene en el artículo 1467 del Código Civil español, que faculta también al vendedor para suspender su obligación de entrega en caso de insolvencia del comprador ${ }^{35}$; y lo que disponen en Sudamérica los artículos 1419 del Código Civil argentino ${ }^{36}, 1688$ del Código Civil uruguayo ${ }^{37}, 1493$ inciso $2^{\circ}$ del Código Civil de Venezuela ${ }^{38}$

“Art. 1467. - Tampoco tendrá obligación el vendedor de entregar la cosa vendida cuando se haya convenido en un aplazamiento o término para el pago, si después de la venta se descubre que el comprador es insolvente, de tal suerte que el vendedor corre inminente riesgo de perder el precio". "Art. 1419. - Tampoco está obligado a entregar la cosa, cuando hubiese concedido un término para el pago, si después de la venta el comprador se halla en estado de insolvencia, salvo si afianzase de pagar en el plazo convenido".

“Art. 1688 (inc. $4^{\circ}$ ). - ...Pero si después del contrato se hallare el comprador en estado de insolvencia o estuvieren sus intereses comprometidos de tal manera que el vendedor corra riesgo inminente de perder el precio no se podrá exigir la entrega, aunque se haya estipulado plazo para el pago de aquel, sino afianzando pagar al vencimiento del plazo".

"Art. 1493 (inc, 2\%). . .. Tampoco está obligado a hacer la entrega, aun cuando haya acordado plazo para el pago del precio, si después de la venta el comprador se hace insolvente o cae en estado de quiebra de suerte que el vendedor se encuentre en peligro inminente de perder el precio, a menos que se dé caución de pagar en el plazo convenido". 
y artículo 495 del Código Civil de Brasil ${ }^{39}$, entre otros. Se trata en estos casos de un incumplimiento previsible, que permite suspender el cumplimiento de las obligaciones correlativas.

No contempla el Código Civil chileno ni los restantes Códigos sudamericanos mencionados, sin embargo, la posibilidad de que el vendedor demande anticipadamente la resolución del contrato a consecuencia de un incumplimiento previsible del comprador, a diferencia de lo que ocurre con el artículo 1503 del Código Civil español respecto de los bienes inmuebles:

"Art. 1503.- Si el vendedor tuviere fundado motivo para temer la pérdida de la cosa inmueble vendida y el precio, podrá promover inmediatamente la resolución de la venta.

Si no existiere este motivo, se observará lo dispuesto en el artículo 1124".

(b) Del mismo modo, siempre en el contrato de compraventa y vistas las cosas por el lado de las obligaciones que atañen al vendedor, el artículo 1872 inciso $2^{\circ}$ del Código Civil chileno faculta aparentemente al comprador para suspender también su obligación de pago cuando es turbado en la posesión de la cosa o si esta, sin saberlo, estaba afecta a una acción real. Dice esta norma:

“...Con todo, si el comprador fuere turbado en la posesión de la cosa o probare que existe contra ella una acción real de que el vendedor no le haya dado noticia antes de perfeccionarse el contrato, podrá depositar el precio con autoridad de la justicia, y durará el depósito hasta que el vendedor haga cesar la turbación o afiance las resultas del juicio".

Nótese, sin embargo, que la norma no exime en modo alguno al comprador de su obligación de pago ni contempla una suspensión propiamente tal de su cumplimiento, sino que solo le confiere el derecho a resguardar su patrimonio mediante la consignación judicial del precio en tanto esa turbación o el juicio respectivo lo afecten, según el caso. De aquí que consideremos más aparente que efectiva esta figura como excepción.

Distinto es el caso del artículo 1502 del Código Civil español ${ }^{40}$,

39 "Art. 495. Nâo obstante o prazo ajustado para o pagamento, se antes da tradição o comprador cair em insolvência, poderá o vendedor sobrestar na entrega da coisa, até que o comprador lhe dê cauçâo de pagar no tempo ajustado."

40 "Art. 1502.- Si el comprador fuere perturbado en la posesión o dominio de la cosa adquirida, o tuviere fundado temor de serlo por una acción reivindicatoria o hipotecaria, podrá suspender el pago del precio hasta que el vendedor haya hecho cesar la perturbación o el peligro, a no ser que afiance la devolución del precio en su caso, o se haya estipulado que, no obstante cualquier contingencia de aquella clase, el comprador estará obligado a verificar el pago." 
1425 del Código Civil argentino ${ }^{41}$ y 1530 del Código Civil de Venezuela $^{42}$, que facultan en estos casos al comprador para suspender derechamente el pago, sin necesidad de consignación alguna. El Código Civil uruguayo, por último, ofrece una solución intermedia en su artículo 1730 , pues por una parte faculta al comprador para suspender el pago, pero por la otra puede ser obligado por el vendedor a depositarlo ${ }^{43}$.

\section{CONCLUSIONES}

Luego de revisar comparativamente el concepto de incumplimiento esencial de los PECL - por una parte- y las normas contenidas en el Código Civil chileno en materia de incumplimiento de obligaciones contractuales -por la otra-, podemos advertir importantes coincidencias en sus aspectos conceptuales fundamentales, existiendo no obstante diferencias sustanciales en cuanto a la forma y oportunidad de provocar la resolución del contrato, como consecuencia de dicho incumplimiento.

En efecto:

$1^{\circ}$. Nos parece, en primer término, que el criterio que en los PECL apunta a la gravedad y efectos del incumplimiento para el acreedor, si bien no encuentra un reconocimiento positivo explícito en el Código Civil chileno, no difiere mayormente en lo medular.

Asimismo, y según se dijo más arriba, se va configurando en Chile una corriente doctrinal, con recientes manifestaciones jurisprudenciales, que destacan la entidad y gravedad del incumplimiento (o cumplimiento parcial) como elemento relevante del análisis y que presentan, por lo mismo, tímidas aunque claras coincidencias con este criterio de incumplimiento esencial.

"Art. 1425.- Si el comprador tuviese motivos fundados de ser molestado por reivindicación de la cosa, o por cualquier acción real, puede suspender el pago del precio, a menos que el vendedor le afiance su restitución".

"Art. 1530. - Si el comprador fuere perturbado o tuviere fundado temor de serlo por una acción sea hipotecaria, sea reivindicatoria, puede suspender el pago del precio hasta que el vendedor haya hecho cesar la perturbación o el peligro, a no ser que el vendedor dé garantia suficiente, o que se haya estipulado que, no obstante cualquiera contingencia de esta clase, el comprador verifique el pago".

"Art. 1730.- Si el comprador es perturbado o tiene fundado temor de serlo por alguna acción real, puede suspender el pago del precio, hasta que el vendedor haya hecho cesar la perturbación o el peligro; a no ser que este último afiance o que se haya estipulado que, no obstante cualquier contingencia, el comprador verifique el pago.

El vendedor que por falta de fianza no puede tomar el precio tiene derecho de obligar al comprador a que lo deposite. El comprador puede también solicitar el depósito para librarse de los intereses, cuando estos se debieren.

Si el comprador ha pagado, antes de la perturbación de que habla el primer inciso, no puede pedir la restitución del precio ni que se le afiance las resultas del juicio". 
$2^{\circ}$. Luego, hemos destacado que las soluciones normativas que se dan para el caso de incumplimiento doloso o intencional son coincidentes, con excepción de la equiparación entre dolo y culpa grave.

$3^{\circ}$. Las diferencias sustanciales no surgen entonces al analizar el concepto y contenido mismo de incumplimiento esencial, sino al definir la forma y la oportunidad en que este puede ser invocado como causa de resolución del contrato.

Desde luego, en los PECL la resolución del contrato no requiere de intervención judicial previa que así lo declare, por sentencia firme o ejecutoriada. Basta para ello la oportuna notificación al deudor ${ }^{44}$.

Asimismo, y en lo que concierne a la figura del incumplimiento previsible, hemos establecido claras diferencias entre los PECL y el sistema regulado en el Código Civil chileno y en los Códigos de los países sudamericanos que hemos mencionado. En todos estos ordenamientos, en efecto, solo aparecen normas similares en materia de contrato de compraventa, las que si bien no facultan a las partes para resolver el contrato cuando el incumplimiento es previsible (como ocurre en los PECL por regla general y en la compraventa regulada en el Código Civil espańol), sí permiten -en mayor o menor medida- suspender el cumplimiento de las obligaciones de entregar la cosa o pagar el precio -según el caso-, a menos que se asegure el cumplimiento de la obligación respectiva.

\section{BIBLIOGRAFÍA}

Abeliuk Manasevich, René (2001). Las Obligaciones, Tomo II, Santiago. Editorial Jurídica de Chile, 1033 pp.

Acquis Group (2007). Principles of Existing EC Contract Law-Contract I- Pre-contractual Obligations, Conclusión of Contract, Unfair Terms Principles of the Existing EC Contract Law (Acquis Principles), Munich: Sellier.

Andreu Martínez, Belén (2003). "Incumplimiento anticipado: regulación en los Principios de Derecho Contractual Europeo y soluciones a la vista del Código civil español", en Espiau Espiau, Santiago / Vaquer Aloy, Antoni (Coords). Bases de un Derecho contractual europeo, Valencia: Tirant lo Blanch, $709 \mathrm{pp}$. optar por la resolución podrá intimar al otro para que ejecute su obligación dentro de un plazo no inferior a quince días, vencido el cual podrá demandar el cumplimiento, o dar por resuelto el contrato con la sola comunicación fehaciente hecha al moroso de haber oprado por la resolución". 
De la Mata, Almudena (2003). “Un paso más hacia la unificación del derecho privado europeo. Comunicación de la Comisión de 15 de marzo de 2003 sobre un derecho contractual europeo más coherente”. Aranzadi Civil, núm. 7-8, Parte Estudio, pp. 2077-2105.

Díez-Picazo, L. / Roca Trías, E. / Morales, A. (2002). Los Principios del derecho europeo de los contratos, Madrid: Civitas, 529 pp.

Fueyo Laneri, Fernando (2004). Cumplimiento e incumplimiento de las obligaciones, Santiago: Editorial Jurídica de Chile, 613 pp.

García Garnica, María del Carmen (2002). "Consideraciones sobre la unificación del Derecho Privado Europeo". Aranzadi Civil, No 7. Disponible en http://nuevo.westlaw.es/wles/app/document?docguid= I285e17c0c73911db8f5d010000000000\&srguid =ia744800e000001 1ae5c6b41c571e71e2 [fecha de consulta: 02 de julio de 2008].

Lando, O. I Beale, H. (2000). Principles of European Contract Law, Parts I and II, The Hague: Kluwer Law International, 561 pp.

López Santa María, Jorge (1986). Los Contratos (Parte General), Santiago: Editorial Jurídica de Chile, 465 pp.

Sánchez Lorenzo, Sixto A. (2002). "Derecho Privado europeo". Estudios de Derecho Privado Europeo, $\mathrm{N}^{\circ} 2,362$ pp.

Schulze, Reiner (2003). "El Derecho Contractual Europeo y sus textos básicos", en AA.VV. Bases de un Derecho contractual europeo, Valencia: Tirant lo Blanch, 709 pp.

Schulze, Reiner (2008). Common Frame of Reference and Existing EC Contract Law, Munich: Sellier, 356 pp.

VÁzquez Lépinette, Tomás (2000). "Compraventa Internacional de Mercaderías. Una visión Jurisprudencial”. Derecho Patrimonial, $\mathrm{N}^{\circ} 2$, $351 \mathrm{pp}$.

\section{Jurisprudencia citada}

Corte Suprema, 31 de marzo de 2003, Rol N 1594-2001, Incomin con ENAMI, juicio arbitral, casación en el fondo, indemnización de perjuicios.

\section{Normas citadas}

PeCL, partes I y II, capítulo VIII, artículos 8.101. y ss.,

Convención de Viena sobre Compraventa Internacional de MercaDERÍAs, artículos 25, 72.

Código Civil, Chile, artículos 44, 1479, 1487 y 1489, 1496, 1538, $1551,1552,1557,1558,1569,1591,1826,1872$.

Código Civil, España, artículos 1102, 1124, 1125, 1127, 1129, 1467, $1502,1503$.

Código Civil, Alemania, artículo 276. 
Código Crvil, Grecia, artículo 332.1.

Código Crvil, Suiza, artículo 100.

Código Civil, Argentina, artículos 1419, 1425.

Código Crvil, Uruguay, artículos 1688, 1730.

Código Crvil, Venezuela, artículos 1493, 1530.

Código Crvil, Brasil, artículo 495.

Diario Oficial de la CE, $\mathrm{N}^{\circ} \mathrm{C} 158$, de 26 de junio de $1989, \mathrm{~N}^{\circ} \mathrm{C} 205$, de 25 julio de 1994.

UnidroIT, Principles of Internacional Comercial Contracts. 
